doi: 10.7250/iscconstrs.2014.14

\title{
VARIATIONAL FORMULATIONS OF THE NONLINEAR EQUILIBRIUM AND STABILITY PROBLEMS OF ELASTIC RODS
}

\author{
Vladimir Lalin ${ }^{1}$, Daria Kushova ${ }^{2}$ \\ ${ }^{1,2}$ Department of Structural Mechanics and Buildings Structures, Institute of Civil Engineering, St. Petersburg State \\ Polytechnical University, Polytechnicheskaya Str. 29, 195251 St. Petersburg, Russia
}

E-mail: ${ }^{1}$ vllalin@yandex.ru; ${ }^{2}$ dasha_kushova@mail.ru

\begin{abstract}
This article is dedicated to the analysis of the nonlinear plane problems formulated in the special CosseratTimoshenko's theory of elastic rods in Lagrangian description. The problems were solved using conjugate pairs of strain and stress vectors. Equivalence of the differential and variational formulations of the Lagrangian functional was proved. The differential equations of the plane problems of stability were obtained from the second variation of the Lagrangian functional. Deformations of bending, shear and tension-compression were taken into account while finding an exact solution for some stability problems.
\end{abstract}

Keywords: large displacements and rotations, conjugate pairs of strain and stress vectors, the functional of variational formulation, the stability equations.

\section{Introduction}

Traditional approach of variational formulation of the nonlinear rod deformation problems is to use the variational equation in the form of principle of virtual displacements (Goloskokov, Zhilin), (Elisseev, 1994), (Zhilin, Sergeev, 1994), (Zhilin, et al. 1997), (Zhilin, 2007), (Eliseev, Zinov'eva, 2008), (Jelenic, Crisfield, 1999),

(Shabana,Yakoub, 2001), (REDDY, 2004), (Antman, 2005), (Gerstmayr, Shabana, 2006), (Shabana, 2008), (Wriggers, 2008), (Krenk, 2009), (Ibrahimbegovic, 2009). In this work, considering the example of plane problem, it is shown that using of the conjugate pairs of strain and stress vectors (Lalin, 2004), the variational problem can be defined as a problem of search for the stationary point of the Lagrangian functional. This allows us to derive the stability equations in two ways: either as equations in variations for the initial differential statement or as the Euler equation for the second variation of the Lagrangian functional.

\section{Problem formulation}

In this paper, the general geometrically nonlinear theory of elastic rods is examined, with bending, shear and tension-compression stiffness being taken into account and no restrictions imposed on displacements and rotations. In the plane problem every point of this rod has three degrees of freedom: two translational degrees and one rotational degree.

We take the disposition of originally rectilinear rod along $\mathrm{X}$ - axis of the right Cartesian coordinate system of $X, Y, Z$ (see Fig. 1a) with unit vectors $\{\mathrm{i}\},\{\mathrm{j}\},\{\mathrm{k}\}$ respectively as the reference unstressed configuration (RC). In RC every point of the rod can be identified by the $\mathrm{x}_{0}$ coordinate, where $0 \leq \mathrm{x}_{0} \leq \mathrm{L}$, $\mathrm{L}$ is length of the unstrained rod.

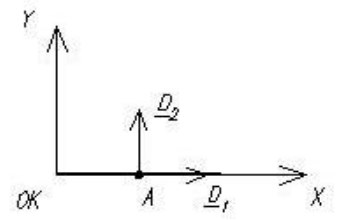

Fig. 1a. Reference configuration (RC) of the rod.
Further the Lagrangian description will be used, where all unknown characteristics depend on $\mathrm{x}_{0}$, and (...)' will denote derivative with respect to $\mathrm{x}_{0}$.

In the special Cosserat theory of elastic rods every point of the rod is connected with three basis vectors of unit length, we denote its vectors as $\left\{D_{i}\right\}$ in the RC. For the originally rectilinear rod without any natural twisting we can assume that $\left\{D_{1}\right\}$ vector is in the direction of the rod axis, $\left\{D_{2}\right\}$ and $\left\{D_{3}\right\}$ vectors are in the directions of the principal central axes of cross section (Fig. 1a), where $\left\{D_{i}\right\}=$ const $\left(x_{0}\right),\left\{D_{1}\right\}=\{i\},\left\{D_{2}\right\}=\{j\}$.

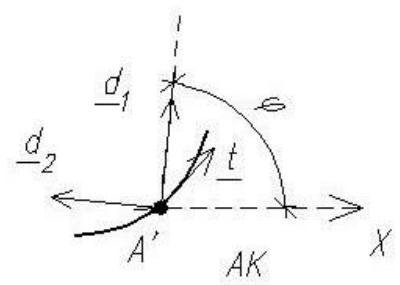

Fig. 1b. Actual (deformed) configuration (AC) of the rod.

Figure $1 \mathrm{~b}$ shows the actual (deformed) configuration of the rod (AC). Position of every point of the rod in the AC can be defined by the vector $\{r\}\left(\mathrm{x}_{0}\right)=\mathrm{x}\left(\mathrm{x}_{0}\right)\{\mathrm{i}\}+$ $+y\left(x_{0}\right)\{j\}$. The basis vectors of unit length in the rotated position are denoted as $\left\{\mathrm{d}_{\mathrm{i}}\right\}=\left\{\mathrm{d}_{\mathrm{i}}\right\}\left(\mathrm{x}_{0}\right)$, where $\left\{\mathrm{d}_{1}\right\}$ vector is not necessarily coincides with $\{\mathrm{t}\}$ - unit vector, tangent to the rod axis in the AC. In the plane problem the rotation of the directors is given by vector $\{\Phi\}\left(\mathrm{x}_{0}\right)=$ $\varphi\left(\mathrm{x}_{0}\right)\{\mathrm{k}\}$. Functions $\mathrm{x}\left(\mathrm{x}_{0}\right), \mathrm{y}\left(\mathrm{x}_{0}\right)$, and $\varphi\left(\mathrm{x}_{0}\right)$ are three degrees of freedom in the plane problems of the geometrically nonlinear deformation of the rod.

The true vectors of stress in the $\mathrm{AC}$ in the plane problem are

$\{\mathrm{f}\}\left(\mathrm{x}_{0}\right)=\mathrm{N}\left(\mathrm{x}_{0}\right)\left\{\mathrm{d}_{1}\right\}+\mathrm{Q}\left(\mathrm{x}_{0}\right)\left\{\mathrm{d}_{2}\right\},\{\mu\}\left(\mathrm{x}_{0}\right)=\mathrm{M}\left(\mathrm{x}_{0}\right)\{\mathrm{k}\}$, the corresponding vectors of strains are:

$\{\mathrm{e}\}\left(\mathrm{x}_{0}\right)=\left\{\mathrm{r}^{\prime}\right\}-\mathrm{P} \cdot\left\{\mathrm{r}_{0}{ }^{\prime}\right\},\{\psi\}\left(\mathrm{x}_{0}\right)=\varphi^{\prime}\{\mathrm{k}\}$ (according to Elisseev (1994) and Zhilin (2007)),

where N - longitudinal force, Q - shearing force, $\mathrm{M}$ - bending moment, $\left\{\mathrm{r}_{0}\right\}=\mathrm{x}_{0}\{\mathrm{i}\}$ - radius-vector of the rod points in the RC, the dot denotes the scalar product, 
$\mathrm{P}\left(\mathrm{x}_{0}\right)$ - turn tensor, the rotation of the $\mathrm{D}_{\mathrm{i}}$ into the $\mathrm{d}_{\mathrm{i}}$ is described by $P: d_{i}=P \cdot D_{i}$, matrix formulation of the turn tensor in the plane problem: $[\mathrm{P}]=\left[\begin{array}{cc}\cos \varphi & -\sin \varphi \\ \sin \varphi & \cos \varphi\end{array}\right]$, back rotation from the $\mathrm{AC}$ into the $\mathrm{RC}$ is described by the transposed tensor $\mathrm{P}^{\mathrm{T}}$.

In the work, Lalin and his colleagues (Lalin, et al. 2013) showed that if the Lagrangian description is used it is more convenient to use the vectors of internal forces and strains turned from the AC into the RC: $\{\mathrm{F}\}=\mathrm{P}^{\mathrm{T}} \cdot\{\mathrm{f}\}$, $\{\mathrm{E}\}=\mathrm{P}^{\mathrm{T}} \cdot\{\mathrm{e}\}$ (turned vectors of moments and of bending deformations in the plane problem coincide with the true vectors). The turned vectors of internal forces and strains are energy conjugate in the sense of the following definition (Lalin, et al. 2013):

$$
\dot{W}=F \cdot \dot{E}+\mu \cdot \dot{\psi},
$$

where $\mathrm{W}=\mathrm{W}(\mathrm{E}, \psi)$ - strain energy density of the elastic (including the nonlinearly elastic) rod, dotted values indicate the time derivative, $W=d W / d t$.

The turned vectors of internal forces and strains in the plane problems:

$\{\mathrm{F}\}\left(\mathrm{x}_{0}\right)=\mathrm{N}\left(\mathrm{x}_{0}\right)\{\mathrm{i}\}+\mathrm{Q}\left(\mathrm{x}_{0}\right)\{\mathrm{j}\}, \mu\left(\mathrm{x}_{0}\right)=\mathrm{M}\left(\mathrm{x}_{0}\right)\{\mathrm{k}\}$,

$\{\mathrm{E}\}\left(\mathrm{x}_{0}\right)=\varepsilon\{\mathrm{i}\}+\Gamma\{\mathrm{j}\},\{\psi\}\left(\mathrm{x}_{0}\right)=\varphi^{\prime}\{\mathrm{k}\}$.

The components of deformations $\varepsilon, \Gamma$ are defined through the functions $\mathrm{x}\left(\mathrm{x}_{0}\right), \mathrm{y}\left(\mathrm{x}_{0}\right)$, and $\varphi\left(\mathrm{x}_{0}\right)$ by geometrical equations (2).

Formulation of the geometrically nonlinear problem for the physically linear rod consists of three sets of equations: (1) - (3).

Equilibrium equations:

$$
\left\{\begin{array}{l}
(N \cos \varphi-Q \sin \varphi)^{\prime}+q_{x}=0 \\
(N \sin \varphi+Q \cos \varphi)^{\prime}+q_{y}=0 \\
M^{\prime}+x^{\prime}(N \sin \varphi+Q \cos \varphi)+ \\
+y^{\prime}(Q \sin \varphi-N \cos \varphi)+m=0
\end{array}\right.
$$

where $\mathrm{q}_{\mathrm{x}}, \mathrm{q}_{\mathrm{y}}$, and $\mathrm{m}$ - distributed power and moment loads respectively.

Geometrical equations:

$\left\{\begin{array}{l}\varepsilon=x^{\prime} \cos \varphi+y^{\prime} \sin \varphi-1 \\ \Gamma=-x^{\prime} \sin \varphi+y^{\prime} \cos \varphi \\ \psi=\varphi^{\prime}\end{array}\right.$

Physics equations:

$N=k_{1} \varepsilon, \quad Q=k_{2} \Gamma, \quad M=k_{3} \psi$

where $\mathrm{k}_{1}, \mathrm{k}_{2}$, and $\mathrm{k}_{3}$ - tension-compression, shear, and bending stiffness of the rod, respectively.

Boundary conditions are:

$$
\begin{aligned}
& x(0)=0, y(0)=0, M(0)=0 \\
& y(L)=0, M(L)=0, N(L)=-T
\end{aligned}
$$

The boundary conditions (4) and (5) correspond to the scheme shown in Figure 2.

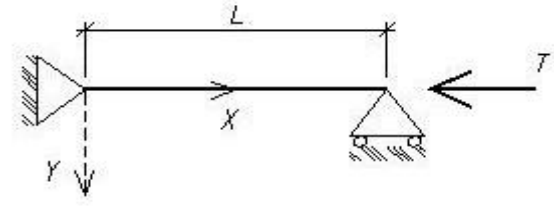

Fig. 2. Design model of the rod.

We assume that in equations (4) - (5) internal forces are expressed in terms of $\mathrm{x}, \mathrm{y}$, and $\varphi$ using equations (2) and (3).

\section{Variational formulation of the static problem}

The Lagrangian functional:

$$
\begin{aligned}
& \Pi(x, y, \varphi)=\int_{o}^{L}\left[\frac { 1 } { 2 } \left(k_{1} \varepsilon^{2}+k_{2} \Gamma^{2}+\right.\right. \\
& \left.\left.+k_{3} \psi^{2}\right)\right] d x_{0}+T(x(L)-L)
\end{aligned}
$$

It is easy to show that equations (1) have resulted from the condition $\delta \Pi=0$, where $\delta \Pi$ - variation of the Lagrangian functional and internal forces are expresses in terms of the $\mathrm{x}, \mathrm{y}$, and $\varphi$ functions. Thus the differential formulation of the problem (1)-(5) is equivalent to the $\Pi \rightarrow$ STAT variational problem of the search of the stationary point of functional (6).

\section{Variational formulation of the stability problem}

Stability equations are the Euler equations of the variational problem $\delta^{2} \Pi \rightarrow$ STAT (Gel'fand, Fomin, 1961), where $\delta^{2} \Pi$ - the second variation of functional (6).

The second variation of functional (6):

$$
\begin{aligned}
& \delta^{2} \Pi\left(\bar{x}, \bar{y}, \bar{\varphi}, h_{1}, h_{2}, f\right)=\int_{o}^{L}(N \varepsilon+Q \Gamma+ \\
& \bar{N} f \Gamma+\bar{N} f\left(h_{2}^{\prime} \cos \bar{\varphi}-h_{1}^{\prime} \sin \bar{\varphi}\right)+ \\
& +\bar{Q} f\left(-h_{2}^{\prime} \sin \bar{\varphi}-h_{1}^{\prime} \cos \bar{\varphi}\right)+\bar{Q} f \varepsilon \\
& \left.+M f^{\prime}\right) d x_{0}
\end{aligned}
$$

In equation (7): $\mathrm{h}_{1}, \mathrm{~h}_{2}$, and $\mathrm{f}-$ variations of functions $\bar{x}$, $\bar{y}$, and $\bar{\varphi}$, respectively; $\mathrm{N}, \mathrm{Q}, \mathrm{M}, \varepsilon, \Gamma, \psi-$ variations of the internal forces and strains correspond to $\mathrm{h}_{1}, \mathrm{~h}_{2}$, and $\mathrm{f}$.

In equation (7) the quantities marked with dashes above them denote the equilibrium state characteristics, satisfying the system of equations (1)-(5). These quantities are characteristics of the equilibrium state, whose stability is studied.

Denoting the $\delta^{2} \Pi \equiv \Phi\left(\bar{x}, \bar{y}, \bar{\varphi}, h_{1}, h_{2}, f\right)$, we find the first variation $\delta \Phi$ of the functional. 
$\delta \Phi=-\int_{o}^{L}\left\{\left[(N \cos \bar{\varphi}-Q \sin \bar{\varphi})^{\prime}-\right.\right.$

$-f^{\prime}(\bar{N} \sin \bar{\varphi}+\bar{Q} \cos \bar{\varphi})-$

$\left.-f(\bar{N} \sin \bar{\varphi}+\bar{Q} \cos \bar{\varphi})^{\prime}\right] d_{1}+$

$+\left[(N \sin \bar{\varphi}+Q \cos \bar{\varphi})^{\prime}+\right.$

$+f^{\prime}(\bar{N} \cos \bar{\varphi}-\bar{Q} \sin \bar{\varphi})+$

$\left.+f(\bar{N} \cos \bar{\varphi}--\bar{Q} \sin \bar{\varphi})^{\prime}\right] d_{2}+$

$+\left[M^{\prime}+\bar{Q} \varepsilon-\bar{N} \Gamma+Q(\bar{\varepsilon}+1)-\right.$

$-\bar{N} \Gamma] g\} d x_{0}+[(N \cos \bar{\varphi}-$

$-Q \sin \bar{\varphi}-\bar{N} f \sin \bar{\varphi}-\bar{Q} f \cos \bar{\varphi}) d_{1}+$

$+(N \sin \bar{\varphi}+Q \cos \bar{\varphi}+\bar{N} f \cos \bar{\varphi}-$

$\left.-\bar{Q} f \sin \bar{\varphi}) d_{2}+M g\right]_{0}^{L}$

where $d_{1}, d_{2}$, and $g$ - variations of functions $h_{1}, h_{2}$, and f respectively.

The Euler equations, resulting from condition $\delta \Phi=0$ for any functions of $\mathrm{d}_{1}, \mathrm{~d}_{2}$, and $\mathrm{g}$, which satisfy the principal boundary conditions of the original meet (1)-(5), are the following equations:

$$
\left\{\begin{array}{l}
(N \cos \bar{\varphi}-Q \sin \bar{\varphi})^{\prime}- \\
-f^{\prime}(\bar{N} \sin \bar{\varphi}+\bar{Q} \cos \bar{\varphi})- \\
-f(\bar{N} \sin \bar{\varphi}+\bar{Q} \cos \bar{\varphi})^{\prime}=0 \\
-(N \sin \bar{\varphi}+Q \cos \bar{\varphi})^{\prime}+ \\
+f^{\prime}(\bar{N} \cos \bar{\varphi}-\bar{Q} \sin \bar{\varphi})+ \\
+f(\bar{N} \cos \bar{\varphi}-\bar{Q} \sin \bar{\varphi})^{\prime}=0 \\
M^{\prime}+\overline{Q \varepsilon}-\bar{N} \Gamma+Q(\bar{\varepsilon}+1)- \\
-\bar{N} \Gamma=0
\end{array}\right.
$$

Thus, equations (9) are the exact equations of the problem of the equilibrium state of the rod for the case of the plane problem.

We would like to stress that the derived system of the stability equations is exact. No simplifying assumptions were made about the displacement and rotation angles quantity, and the character of the equilibrium state of the rod.

\section{Examples of the solutions of the equilibrium stability problems}

Let us take the rod shown in Figure 2 as an example.

The equilibrium configuration is rectilinear, with only $\mathrm{T}$ - compression force acting.

We will denote the Lagrangian coordinate as $\mathrm{x}$ and the equilibrium state characteristics as values with the inferior index 0 .

For this example:

$$
\begin{aligned}
& M_{0}=0, Q_{0}=0, \varphi_{0}=0, \Gamma_{0}=0, q_{y}=0, \\
& y_{0}=0, q_{x}=0 . \\
& N_{0}=-T, \varepsilon_{0}=x_{0}{ }^{\prime}-1=\frac{N_{0}}{k_{1}} . \\
& \cos \varphi_{0}=1, \quad \sin \varphi_{0}=0 .
\end{aligned}
$$

For the sake of convenience we will use the standard notations for the variations:

$$
h_{1}=u, h_{2}=v, f=\theta
$$

Thus, the stability equations can be written in the following way:

$$
\begin{aligned}
& \left\{\begin{array}{l}
N^{\prime}=0 \\
-T \theta^{\prime}+Q^{\prime}=0 \\
M^{\prime}+Q\left(1-\frac{T}{k_{1}}\right)+T\left(-x_{0}^{\prime} \theta+v^{\prime}\right)=0
\end{array}\right. \\
& \left\{\begin{array}{l}
\varepsilon=u^{\prime} \\
\Gamma=-x_{0}^{\prime} \theta+v^{\prime} \\
\psi=\theta^{\prime}
\end{array}\right. \\
& \left\{\begin{array}{l}
N=k_{1} u^{\prime} \\
Q=k_{2}\left(-x_{0}^{\prime} \theta+v^{\prime}\right) \\
M=k_{3} \theta^{\prime}
\end{array}\right.
\end{aligned}
$$

Then, for the homogeneous rod, whose stiffness does not depend on $\mathrm{x}$, we obtain the following system:

$$
\left\{\begin{array}{l}
k_{1} u^{\prime \prime}=0 \\
-T \theta^{\prime}+k_{2}\left[v^{\prime}-\left(1-\frac{T}{k_{1}}\right) \theta\right]^{\prime}=0 \\
k_{3} \theta^{\prime \prime}+k_{2}\left[v^{\prime}-\left(1-\frac{T}{k_{1}}\right) \theta\right]\left(1-\frac{T}{k_{1}}+\frac{T}{k_{2}}\right)=0
\end{array}\right.
$$

In the derived system (11) the first equation describes the longitudinal deformations and does not depend on the second and third equations. Consequently, the stability is verified only by the second and third equations.

Stability functional for the second and third equation can be written as:

$$
\begin{aligned}
& \Phi(v, \theta)=\int_{o}^{L} k_{2}\left(v^{\prime}-\left(1-\frac{T}{k_{1}}\right) \cdot \theta\right)^{2}+k_{3} \theta^{\prime 2}- \\
& -T \theta\left(2 v^{\prime}-\left(1-\frac{T}{k_{1}}\right) \cdot \theta\right) d x_{0} .
\end{aligned}
$$

The general solution of the second and third equations of system (11), containing four arbitrary constants $\mathrm{C}_{1}-\mathrm{C}_{4}$, can be written in the following way:

$$
\begin{aligned}
& v(s)=-C_{1} \frac{A}{\lambda} \cos \lambda s+C_{2} \frac{A}{\lambda} \sin \lambda s+ \\
& C_{3}\left(1-\frac{k_{2} A}{T}\right) s+C_{4} \\
& \theta(\mathrm{s})=C_{1} \sin \lambda s+C_{2} \cos \lambda s-C_{3} \frac{k_{2}}{T},
\end{aligned}
$$

where:

$\mathrm{A}=1+\mathrm{T}\left(\frac{1}{\mathrm{k}_{2}}-\frac{1}{\mathrm{k}_{1}}\right), \quad \lambda^{2}=\frac{T A}{k_{3}}$. 
Using the boundary conditions, we define the arbitrary constants. For the hinged rod boundary conditions are:

$v(0)=v(L)=0$

If $M=k_{3} \theta^{\prime}, \quad M(0)=M(L)=0$,

so $\theta^{\prime}(0)=\theta^{\prime}(L)=0$

Using conditions (13), we have the following:

$c_{1}=0, c_{3}=0, c_{4}=0$

$\theta(x)=c_{2} \cos \lambda x ; \theta^{\prime}(L)=-c_{2} \sin \lambda L=0$

Examining the solution of the equation $\sin \lambda \mathrm{L}=0$ $\lambda L=\pi n$, where $\mathrm{n}=1,2,3 \ldots$, we can find that the critical (minimal) force value is obtained at $n=1$ and calculated from the quadratic equation (Lalin et al. 2013):

$T^{2}\left(\frac{1}{k_{2}}-\frac{1}{k_{1}}\right)+T-T_{\ni}=0$,

where $\mathrm{T}_{\ni}-$ Euler's force for the hinged rod (Perel'muter\& Slivker 2010), equating $T_{\ni}=\pi^{2} k_{3} / L^{2}$.

Hence, we obtain a unique positive value $\mathrm{T}$ :

$$
T=\frac{\sqrt{1+4 T_{\ni}\left(\frac{1}{k_{2}}-\frac{1}{k_{1}}\right)}-1}{2\left(\frac{1}{k_{2}}-\frac{1}{k_{1}}\right)}
$$

Solution (15) is the exact solution of the problem of the hinged rod when tension-compression, shear and bending stiffness are taken into account. Further we examine some particular cases.

Examining the case of high tension-compression stiffness: $1 / k_{1}=0$, we obtain:

$$
T=\frac{k_{2}}{2}\left(\sqrt{1+\frac{4 T_{\ni}}{k_{2}}}-1\right) \text {. }
$$

Solution (16) is the exact solution of the problem of the hinged rod when shear and bending stiffness are taken into account.

Let us examine the case of high shear stiffness: $1 / k_{2} \rightarrow 0$.

Expanding equation (16) radicand into a series and taking into account the summands of the first and of the second order of smallness, we have:

$$
\begin{aligned}
& T=\frac{k_{2}}{2}\left(\sqrt{1+\frac{4 T_{\ni}}{k_{2}}}-1\right)=\frac{k_{2}}{2}(1+ \\
& \left.+\frac{1}{2} \frac{4 T_{\ni}}{k_{2}}-\frac{1}{4 \cdot 2 !}\left(\frac{4 T_{\ni}}{k_{2}}\right)^{2}-1\right)=T_{\ni}\left(1-\frac{T_{\ni}}{k_{2}}\right)
\end{aligned}
$$

Finally, we obtain: $T=T_{\ni}\left(1-T_{\ni} / k_{2}\right)$

Solution (17) accurate within the smallness of the second order coincides with the known Engesser approximate solution (Perel'muter \& Slivker 2010):

$$
T=T_{\ni}\left(1+T_{\ni} / k_{2}\right)^{-1}
$$

Expanding the radicand in solution (16) into a series and taking into account the summands of the first order of smallness, we have:

$$
\begin{aligned}
& T=\frac{k_{2}}{2}\left(\sqrt{1+\frac{4 T_{\ni}}{k_{2}}}-1\right) \\
& =\frac{k_{2}}{2}\left(1+\frac{1}{2} \frac{4 T_{\ni}}{k_{2}}-1\right)=T_{\ni} .
\end{aligned}
$$

Thus, if $1 / k_{1} \rightarrow 0$ и $1 / k_{2} \rightarrow 0$, from the solution (15), according to equation (19), the Euler's classical solution can be derived.

To estimate the measure of inaccuracy of Engesser formula (18) we express exact solution (16) and (18) by the non-dimensional coefficients $T_{\ni} / k_{2}$ and plot the graph for both formulas. Figure 3 shows the graphs for the stud of the three meters long, made of the 20UC1 double tee stud, as an example.

The vertical line corresponds to the 5\%-difference between the exact value (16) and the value, obtained with the Engesser formula (18). The values, situated to the left of the line, correspond to the under $5 \%$-difference, and to the right - to the above 5\%-difference. Thus, it can be concluded, that the Engesser formula results in a conservative estimate of critical load.

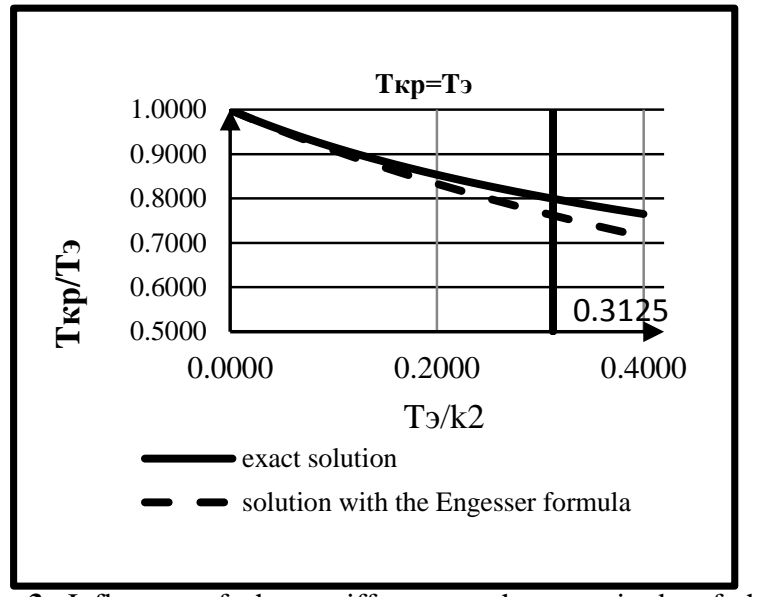

Fig. 3. Influence of shear stiffness on the magnitude of the critical force for the exact solution and for the solution with the Engesser formula.

In the same way we have obtained the exact solutions of the stability problems for different types of end fixity of the rod. Boundary conditions for different types of end fixity of the rod can be written in the following way ((20)-(23)):

$$
\begin{aligned}
& v(0)=0 ; \quad \theta(0)=0 ; \quad \theta^{\prime}(L)=0 \\
& \mathrm{k}_{2}\left[\mathrm{v}^{\prime}-\theta\left(1-\frac{\mathrm{T}}{\mathrm{k}_{1}}\right)\right]-\left.\mathrm{T} \theta\right|_{S=L}=0 \\
& v(0)=v(L)=0 \\
& \theta(0)=\theta(L)=0
\end{aligned}
$$




$$
\begin{array}{ll}
v(0)=v(L)=0 \\
\theta(0)=0 ; & \theta^{\prime}(L)=0 \\
v(0)=0 ; & Q(L)=0 \\
\theta(L)=0 ; & \theta^{\prime}(0)=0
\end{array}
$$

The Euler's force value for boundary conditions (20), (23) is $T_{\text {э }}=\pi^{2} k_{3} /\left(4 L^{2}\right)$, for boundary conditions (21) $T_{\ni}=4 \pi^{2} k_{3} / L^{2}$, and for boundary conditions (22) $T_{\ni}=\pi^{2} k_{3} / L^{2}$.

\section{Conclusions}

1. The formulation of the static problems of the geometrically nonlinear deformation of the elastic beam was obtained as a system of the differential equations using conjugate pairs of strain and stress vectors.

2. The Lagrangian functional for the variational formulation of the static problems of the geometrically nonlinear rods was proposed.

3. The equivalence of the variational and differential formulations was proved.

4. The equations of the plane problems of the equilibrium stability as the Euler's equations for the second variation of the Lagrangian functional were obtained.

5. The exact solutions of the equilibrium stability problems for different types of end fixity of the rod were obtained taking into account bending, shear and tension stiffness.

6. It has been shown that the Engesser formula results in a conservative estimate of critical load in comparison with the exact solution.

\section{References}

Goloskokov, D.P.; Zhilin, P.A., Obshhaja nelinejnaja teorija uprugih sterzhnej $s$ prilozheniem $k$ opisaniju jeffekta Pojntinga. Deponiroano VINITI, pp.1912-V87 Dep., 20 s.

Elisseev, V.V., 1994. Mehanika uprugih sterzhnej. SPb, Izd-vo SPbGPU, $88 \mathrm{~s}$

Zhilin, P.A.; Sergeev, A.D., 1994. Ravnovesie i ustojchivost tonkogo sterzhnja, nagruzhennogo konservativnym momentom, Mehanika $i$ processy upravlenija. Trudy SPbGTU,448, S.47-56.
Zhilin, P.A.; Sergeev, A.D.; Tovstik, T.P., 1997. Nelinejnaja teorija sterzhnej $i$ ee prilozhenija.Trudy XXIV letnej shkoly "Analiz $i$ sintez nelinejnyh mehanicheskih kolebatel'nyh sistem». Sankt-Peterburg, S. 313-337.

Zhilin, P. A., 2007. Prikladnaja mehanika. Teorija tonkih uprugih sterzhnej. SPb, Izd-vo SPbGPU. $102 \mathrm{~s}$.

Eliseev, V. V.; Zinov'eva, T. V., 2008. Mehanika tonkostennyh konstrukcij. Teorija sterzhnej. SPb, Izd-vo SPbGPU. 96 s.

Jelenic, G.; Crisfield, M. A., 1999. Geometrically exact 3D beam theory: implementation of a strain-invariant finite element for static and dynamics. Comp. Meths. Appl. Mech. Eng. 171, pp. 141-171. http://dx.doi.org/10.1016/S0045-7825(98)00249-7

Shabana, A. A.; Yakoub, R. Y., 2001. Three dimensional absolute nodal coordinate formulation for beam elements: theory. ASME Journal of Mechanical Design, 123(4), pp. 606-613. http://dx.doi.org/10.1115/1.1410100

Reddy, J. N., 2004. An Introduction to Nonlinear Finite Element Analysis. Oxford University Press, 482 p. http://dx.doi.org/10.1093/acprof:oso/9780198525295.001.0001

Antman, S. S., 2005. Nonlinear problems of elasticity. Springer, Berlin Heidelberg New York, 835 p.

Gerstmayr, J.; Shabana, A. A., 2006. Analysis of thin beams and cables using the absolute nodal coordinate formulation. Nonlinear Dyn. 45(1-2), pp.109-130. http://dx.doi.org/10.1007/s11071-006-1856-1

Shabana, A. A., 2008. Computational continuum mechanics. Cambridge University Press, 349 p. http://dx.doi.org/10.1017/CBO9780511611469

Wriggers, P., 2008. Nonlinear finite element methods. SpringerVerlag Berlin Heidelberg, 566 p.

Krenk, S., 2009. Nonlinear modelling and analysis of solids and structures. Cambridge University Press, $361 \mathrm{p}$.

Ibrahimbegovic, A., 2009. Nonlinear Solid Mechanics. Springer Science+Business Media B.V. 585 p.

Lalin, V. V., 2004. Razlichnye formy uravnenij nelinejnoj dinamiki uprugih sterzhnej. Trudy SPbGPU, 489. S. 121-128.

Gelfand, I. M.; Fomin, S. V., 1961. Variacionnoe ischislenie. M.: GIFML, $228 \mathrm{~s}$.

Lalin, V. V.; Rozin, L. A.; Kushova, D. A., 2013. Variacionnaja postanovka ploskoj zadachi geometricheski nelinejnogo deformirovanija i ustojchivosti uprugih sterzhnej. Inzhenerno-stroitel'nyj zhurnal. 1 (36), pp. 87-96.

Perelmuter, A. B.; Slivker, V. I., 2010. Ustojchivost' ravnovesija konstrukcij $i$ rodstvennye problemy. Tom1. M.: Izdatel'stvo SKAD SOFT, $704 \mathrm{~s}$. 